\title{
Numerical Simulation of Wave Overtopping on a Porous Breakwater Using Boussinesq Equations Boussinesq 방정식을 사용하여 투수방파제의 월파 수치해석
}

\author{
Thanh Thu Huynh*, Changhoon Lee* and Suk Jin Ahn** \\ 휜탄트* . 이창훈* 안석진**
}

\begin{abstract}
We obtain height of waves overtopping on a porous breakwater using both the one-layer and two-layer Boussinesq equations. The one-layer Boussinesq equations of Lee et al. (2014) are used and the two-layer Boussinesq equations are derived following Cruz et al. (1997). For solitary waves overtopping on a porous breakwater, we find through numerical experiments that the height of waves overtopping on a low-crested breakwater (obtained by the Navier-Stokes equations) are smaller than the height of waves passing through a highcrest breakwater (obtained by the one-layer Boussinesq equations) and larger than the height of waves passing through a submerged breakwater (obtained by the two-layer Boussinesq equations). As the wave nonlinearity becomes smaller or the porous breakwater width becomes narrower, the heights of transmitting waves obtained by the one-layer and two-layer Boussinesq equations become closer to the height of overtopping waves obtained by the Navier-Stokes equations.
\end{abstract}

Keywords : Boussinesq equations, Navier-Stokes equations, porous breakwater, overtopping, numerical experiment

요 지 : 1개층 Boussinesq 방정식과 2개층 Boussinesq 방정식을 사용하여 투수방파제를 지나는 파랑의 월파고를 구 하였다. 1개층 Boussinesq 방정식으로 Lee 등(2014)이 유도한 식을 사용하였고, 2개층 Boussinesq 방정식은 Cruz 등 (1997)의 방법을 따라서 유도하였다. 수치실험을 통해 천단고가 낮은 투수방파제를 지나는 고립파의 월파고(NavierStokes 방정식으로 구함)가 천단고가 높은 투수방파제를 지나는 통과파고(1개층 Boussinesq 방정식으로 구함)보다 더 작고, 천단고가 해저에 있는 투수방파제를 지나는 통과파고(2개층 Boussinesq 방정식으로 구함)보다 더 크다는 것 을 확인하였다. 고립파의 파고가 낮을수록 또는 투수방파제의 폭이 좁을수록 1 개층 및 2 개층 Boussinesq 방정식으 로 구한 통과파고가 Navier-Stokes 방정식으로 구한 월파고에 근접한 것을 확인하였다.

핵심용어 : Boussinesq 방정식, Navier-Stokes 방정식, 투수 방파제, 월파, 수치실험

\section{Introduction}

Wave overtopping on a breakwater may cause damage to coastal structures as well as injuries and life losses to people. In reality, wave overtopping is a three-dimensional phenomenon due to refraction and diffraction because usually waves propagate obliquely on coastal structures. Usually, people use three-dimensional equations such as the Reynolds Averaged Navier-Stokes equations, e.g., COBRAS (Lin and Liu, 1998) and CASMAS-SURF (CDIT, 2001) or the smooth particle hydrodynamics method (Gingold and Monaghan, 1977) to simulate wave overtopping. Simulation of the three-dimensional equations in a horizontal two- dimensional domain requires so long running time. Hence, coastal engineers simulate wave overtopping only for normally incident waves. The Boussinesq equations are depth-averaged two-dimensional equations. Thus, simulation of the Boussinesq equations in a horizontal two-dimensional domain does not require so long running time. For waves overtopping on a porous breakwater, there may exist open space between the bottom and the water surface. The Boussinesq equations assume that there should not be any open space. Thus, in some case, the Boussinesq equations cannot simulate overtopping of waves on a porous breakwater. The Boussinesq equations were developed for waves on a porous bed by Cruz et al. (1997). The equations

\footnotetext{
*Department of Civil \& Environmental Engineering, Sejong University (Corresponding author: Changhoon Lee, Department of Civil \& Environmental Engineering, Sejong University, Seoul 05006, Korea, Tel: +82-2-3408-3294, Fax: +82-2-3408-4332, clee@sejong.ac.kr)

**Research Institute, GeoSystem Research Corporation
} 
consider waves in two layers, i.e., a upper free layer and a lower porous layer. In the present study, we extend Cruz et al.'s Boussinesq equations to analyze waves in two porous layers with different porosities. Recently, the Boussinesq equations are developed for waves in a porous layer by Lee et al. (2014). The equations consider waves in one porous layer. The waves overtopping on a low-crested porous breakwater would experience energy dissipation more than waves through a high-crested breakwater and less than waves passing through a submerged porous breakwater. Thus, the height of waves overtopping on a low-crested porous breakwater which can be simulated using the Navier-Stokes equations (CDIT, 2001) is greater than that of waves passing through a high-crested porous breakwater which can be simulated using the one-layer Boussinesq equations (Lee et al., 2014) and also it is less than that of waves passing through a submerged breakwater which can be simulated using the two-layer Boussinesq equations
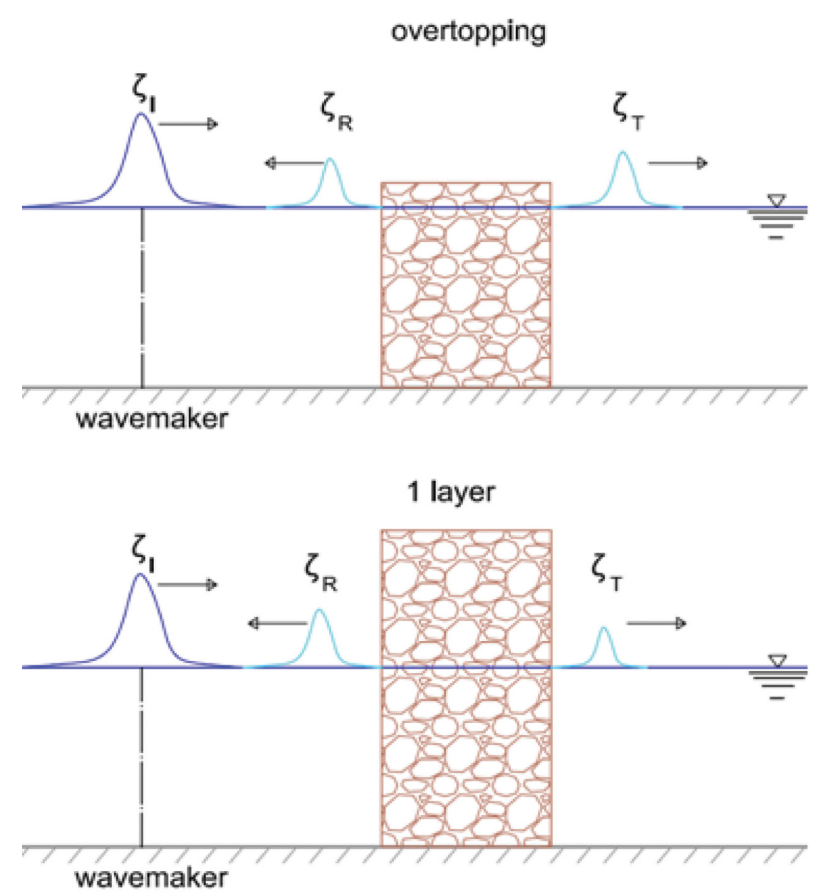

2 layers

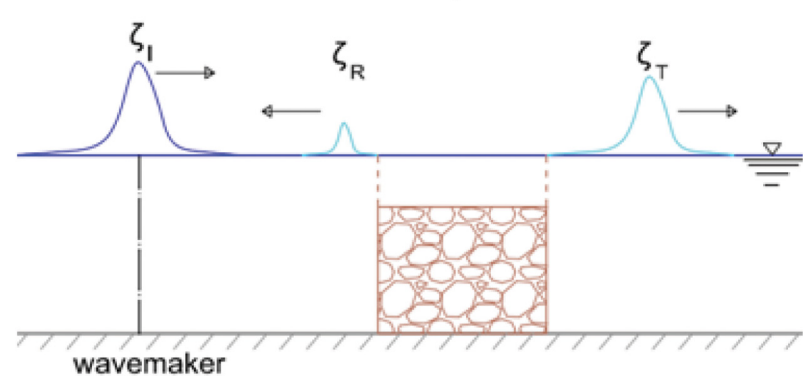

Fig. 1. Waves overtopping and transmitting a porous breakwater.
(Cruz et al., 1997). Fig. 1 shows three cases of waves passing on porous breakwaters.

In this study, we approximately obtain the heights of solitary waves overtopping on porous breakwaters using the one- and two-layer Boussinesq equations. In Section 2, we describe theory of the one-layer and two-layer Boussinesq equations and the Navier-Stokes equations. In Section 3, we conduct numerical experiments to find optimum values of the drag and inertial coefficients which are used in the Boussinesq equations and the Navier-Stokes equations and to find the height of waves overtopping on a low-crested porous breakwater is between that of waves passing through a high-crested porous breakwater and a submerged porous breakwater. In section 4 , we summarize the present study and suggest the future study.

\section{Theory}

\subsection{Drag and inertial resistance coefficients}

In the present Boussinesq equations for both cases of one and two layers, the momentum equation can be expressed as

$$
\beta \frac{d U}{d t}+\frac{1}{\rho} \nabla_{3}(p+\rho g z)+\alpha U=0
$$

where $U(=(u, v, w))$ is the three-dimensional seepage velocity vector, $p$ is the pressure, $\rho$ is the density of water, $g$ is the gravitational acceleration, $\beta=\lambda+(1-\lambda)(1+\kappa)$ and $\alpha=\alpha_{l}[(1-\lambda) / \lambda]^{2} v / d^{2}+\alpha_{t}[(1-\lambda) / \lambda]|U| / d$ are the inertial and drag resistance coefficients (Ergun, 1952), respectively, $\alpha_{1}$ and $\alpha_{t}$ are the laminar and turbulent drag resistance coefficients, respectively, $\lambda$ is the porosity, $d$ is the porous material size, $v$ is the kinematic viscosity of water, $\kappa$ is the added mass coefficient, and $\left.\nabla_{3}(=\partial / \partial x, \partial / \partial y, \partial / \partial z)\right)$ is the three-dimensional gradient operator. The seepage velocity $U$ is related to the discharge velocity $U^{\prime}$ as $U=U^{\prime} / \lambda$. We use the CADMAS-SURF (CDIT, 2001) for the NavierStokes equations model. The CADMAS-SURF was developed by the Coastal Development Institute of Technology, Japan. In the CADMAS-SURF, the momentum equation can be expressed as

$$
\beta_{c} \frac{d U}{d t}+\frac{\lambda}{\rho} \nabla_{3}(p+\rho g z)+\alpha_{c} U=0
$$

where $\beta_{c}=\lambda+(1-\lambda)(1+\kappa)$ and $\alpha_{c}=\alpha_{l E}\left[(1-\lambda)^{3} / \lambda\right] v$ $d^{2}+\alpha_{t E}[(1-\lambda) / \lambda]|U| / d$ are the inertial and drag resistance coefficients (Engelund, 1953), respectively, $\alpha_{I E}$ and $\alpha_{t E}$ are 
the laminar and turbulent drag resistance coefficients, respectively. The inertial and drag resistance coefficients between eqs. (1) and (2) are related as

$$
\beta=\beta_{c}, \alpha_{l}=\lambda(1-\lambda) \alpha_{I E}, \alpha_{t}=\alpha_{t E}
$$

\subsection{Governing equations of the Boussinesq equations} and the Navier-Stokes equations

The one-layer Boussinesq equations (Lee et al., 2014) are derived from the continuity and boundary conditions in dimensionless form as

$$
\begin{aligned}
& \mu^{2} \nabla^{2} \Phi+\frac{\partial^{2} \Phi}{\partial z^{2}}=0,-h \leq z \leq \varepsilon \zeta \\
& \mu^{2}\left(\beta \frac{\partial \Phi}{\partial t}+\alpha \Phi+\zeta\right)+\varepsilon \beta \frac{1}{2}\left[\mu^{2}(\nabla \Phi)^{2}+\left(\frac{\partial \Phi}{\partial z}\right)^{2}\right]=0 \\
& \quad z=\varepsilon \zeta \\
& \frac{\partial \Phi}{\partial z}=\mu^{2}\left(\frac{\partial \zeta}{\partial t}+\varepsilon \nabla \Phi \cdot \nabla \zeta\right), z=\varepsilon \zeta \\
& \frac{\partial \Phi}{\partial z}=-\mu^{2} \nabla \Phi \cdot \nabla h, z=-h
\end{aligned}
$$

where $\Phi$ is the velocity potential, $\zeta$ is the water surface elevation, $h$ is the mean water depth, $\nabla(=(\partial / \partial x, \partial / \partial y))$ is the horizontal gradient operator, and $\mu\left(=h_{0} / l\right)$ and $\varepsilon\left(=a / h_{0}\right)$ is the wave dispersiveness and nonlinearity parameters, respectively. Eq. (4) is the continuity equation, Eqs. (5) and (6) are the dynamic and kinematic boundary conditions on free surface and Eq. (7) is the bottom boundary condition. The velocity potential is expressed as a power series in vertical coordinate given by

$$
\Phi(x, y, z, t)=\sum_{n=0}^{\infty}[z+h(x, y)]^{n} \phi_{n}(x, y, t)
$$

Following Cruz et al. (1997), Lee et al. (2014) derived the extended Boussinesq equations for deeper water in dimensional form as

$$
\begin{aligned}
& \frac{\partial \zeta}{\partial t}+\nabla \cdot[(h+\zeta) u]=0 \\
& \left(\beta \frac{\partial}{\partial t}+\alpha\right) u+\beta u \cdot \nabla u+g \nabla \zeta+\frac{1}{6}\left(\beta \frac{\partial}{\partial t}+\alpha\right) h^{2} \nabla(\nabla \cdot u) \\
& \quad-\left(\frac{1}{2}+\gamma\right)\left(\beta \frac{\partial}{\partial t}+\alpha\right) h \nabla[\nabla \cdot(h u)]-\gamma g h \nabla[\nabla \cdot(h \nabla \zeta)]=0
\end{aligned}
$$

where $u(=(u, v))$ is the horizontal seepage velocity vector, $\gamma(=1 / 18)$ is a parameter to improve the dispersion relation in deeper waters, and Eqs. (9) and (10) are the continuity and momentum equations. For non-porous layer (i.e., $\beta=1$ and $\alpha=0$ ), the momentum equation (10) becomes Madsen and Sørensen's (1992) equation given by

$$
\begin{aligned}
\frac{\partial u}{\partial t}+u & \cdot \nabla u+g \nabla \zeta+\frac{1}{6} h^{2} \nabla\left(\nabla \cdot \frac{\partial u}{\partial t}\right) \\
& -\left(\frac{1}{2}+\gamma\right) h \nabla\left[\nabla \cdot\left(h \frac{\partial u}{\partial t}\right)\right]-\gamma g h \nabla[\nabla \cdot(h \nabla \zeta)]=0
\end{aligned}
$$

And further, if $\gamma=0$, the momentum equation (11) becomes Peregrine's (1967) equation given by

$$
\begin{gathered}
\frac{\partial u}{\partial t}+u \cdot \nabla u+g \nabla \zeta+\frac{1}{6} h^{2} \nabla\left(\nabla \cdot \frac{\partial u}{\partial t}\right) \\
-\frac{1}{2} h \nabla\left[\nabla \cdot\left(h \frac{\partial u}{\partial t}\right)\right]=0
\end{gathered}
$$

In the present study, we derive the Boussinesq equations for waves in two porous layers. For waves in two porous layers, there are two water depths $h_{1}$ and $h_{2}$ measured from the mean water level (see Fig. 2).

The continuity and boundary conditions in dimensionless form are given below

$$
\begin{aligned}
& \mu^{2} \nabla^{2} \Phi_{1}+\frac{\partial^{2} \Phi_{1}}{\partial z^{2}}=0,-h_{1} \leq z \leq \varepsilon \zeta \\
& \mu^{2} \nabla^{2} \Phi_{2}+\frac{\partial^{2} \Phi_{2}}{\partial z^{2}}=0,-h_{2} \leq z \leq-h_{1} \\
& \mu^{2}\left(\beta_{1} \frac{\partial \Phi_{1}}{\partial t}+\alpha_{1} \Phi_{1}+\zeta\right) \\
& +\varepsilon \beta_{1} \frac{1}{2}\left[\mu^{2}\left(\nabla \Phi_{1}\right)^{2}+\left(\frac{\partial \Phi_{1}}{\partial z}\right)^{2}\right]=0, z=\varepsilon \zeta \\
& \frac{\partial \Phi_{1}}{\partial z}=\mu^{2}\left(\frac{\partial \zeta}{\partial t}+\varepsilon \nabla \Phi_{1} \cdot \nabla \zeta\right), z=\varepsilon \zeta
\end{aligned}
$$

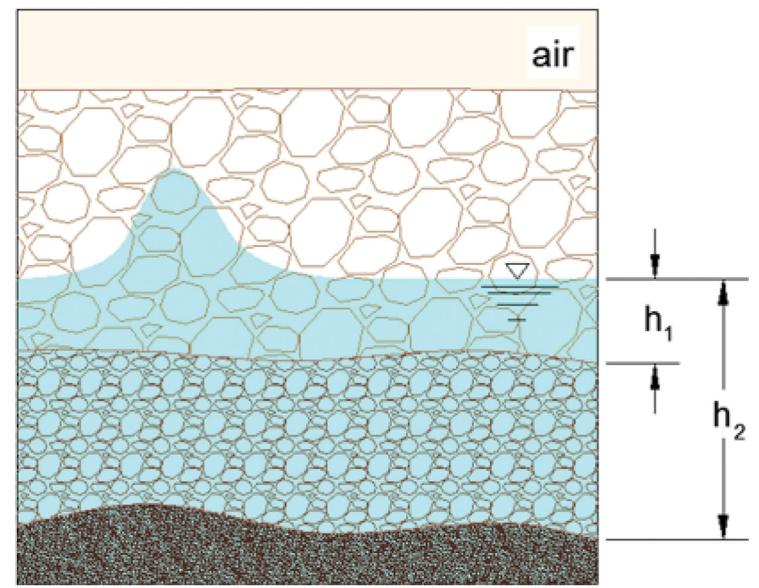

Fig. 2. Water depth $h_{1}$ and $h_{2}$ for two porous layers. 


$$
\begin{aligned}
\mu^{2}\left(\beta_{1} \frac{\partial \Phi_{1}}{\partial t}+\alpha_{1} \Phi_{1}\right)+\varepsilon \beta_{1} \frac{1}{2}\left[\mu^{2}\left(\nabla \Phi_{1}\right)^{2}+\left(\frac{\partial \Phi_{1}}{\partial z}\right)^{2}\right] \\
=\mu^{2}\left(\beta_{2} \frac{\partial \Phi_{2}}{\partial t}+\alpha_{1} \Phi_{2}\right)+\varepsilon \beta_{2} \frac{1}{2}\left[\mu^{2}\left(\nabla \Phi_{2}\right)^{2}+\left(\frac{\partial \Phi_{2}}{\partial z}\right)^{2}\right] \\
z=-h_{1} \\
\lambda_{1}\left(\frac{\partial \Phi_{1}}{\partial z}+\mu^{2} \nabla \Phi_{1} \cdot \nabla h_{1}\right)=\lambda_{2}\left(\frac{\partial \Phi_{2}}{\partial z}+\mu^{2} \nabla \Phi_{2} \cdot \nabla h_{1}\right) \\
z=-h_{1} \\
\frac{\partial \Phi_{2}}{\partial z}=-\mu^{2} \nabla \Phi_{2} \cdot \nabla h_{2}, z=-h_{2}
\end{aligned}
$$

Eqs. (13) and (14) are the continuity equations for the upper and lower layers, respectively. Eqs. (15) and (16) are the dynamic and kinematic boundary conditions on free surface. Eqs. (17) and (18) are the dynamic and kinematic boundary conditions at the interface between the upper and lower layers. Eq. (19) is the bottom boundary condition. In Eqs. (13) to (19), the subscripts 1 and 2 imply the corresponding variables in the upper and lower layers, respectively. The velocity potentials are expressed as a power series in vertical coordinate given by

$$
\begin{aligned}
& \Phi_{1}(x, y, z, t)=\sum_{n=0}^{\infty}\left[z+h_{1}(x, y)\right]^{n} \phi_{1, n}(x, y, t) \\
& \Phi_{2}(x, y, z, t)=\sum_{n=0}^{\infty}\left[z+h_{2}(x, y)\right]^{n} \phi_{2, n}(x, y, t)
\end{aligned}
$$

Following Cruz et al. (1997), we derive the extended Boussinesq equations for deeper water in dimensional form as

$$
\begin{aligned}
\frac{\partial \zeta}{\partial t}+\nabla \cdot\left[\left(h_{1}+\zeta\right) u_{1}\right]+\frac{\lambda_{2}}{\lambda_{1}} \nabla \cdot\left[\left(h_{2}-h_{1}\right) u_{2}\right]=0 \\
\left(\beta_{1} \frac{\partial}{\partial t}+\alpha_{1}\right) u_{1}+\beta_{1} u_{1} \cdot \nabla u_{1}+g \nabla \zeta+\frac{1}{2}\left(\beta_{1} \frac{\partial}{\partial t}+\alpha_{1}\right) \\
\\
\quad\left\langle\frac{h_{1}^{2}}{3} \nabla\left(\nabla \cdot u_{1}\right)-h_{1} \nabla\left\{\frac{\lambda_{2}}{\lambda_{1}} \nabla \cdot\left[\left(h_{2}-h_{1}\right) u_{2}\right]\right\}\right) \\
\quad-\left(\frac{1}{2}+\gamma_{1}\right)\left(\beta_{1} \frac{\partial}{\partial t}+\alpha_{1}\right) h_{1} \nabla\left[\nabla \cdot\left(h_{1} u_{1}\right)\right] \\
\quad-\gamma_{1} g h_{1} \nabla\left[\nabla \cdot\left(h_{1} \nabla \zeta\right)\right]=0 \\
\left(\beta_{2} \frac{\partial}{\partial t}+\alpha_{2}\right) u_{2}+\beta_{2} u_{2} \cdot \nabla u_{2}+g \nabla \zeta+\frac{1}{2}\left(\beta_{2} \frac{\partial}{\partial t}+\alpha_{2}\right) \\
\\
\quad-\frac{2}{3}\left(h_{2}-h_{1}\right)^{2} \nabla\left(\nabla \cdot u_{2}\right)-\left(h_{2}-h_{1}\right) \nabla\left(\nabla h_{2} \cdot u_{2}\right) \\
\left.\quad-\left(h_{2}-h_{1}\right) \nabla\left(h_{2}-2 h_{1}\right) \nabla \cdot u_{2}+2 \nabla h_{1} \nabla h_{2} \cdot u_{2}\right] \\
\quad-\frac{1}{2}\left(\beta_{1} \frac{\partial}{\partial t}+\alpha_{1}\right) \nabla\left[\nabla \cdot\left(h_{1}^{2} u_{1}\right)\right]
\end{aligned}
$$




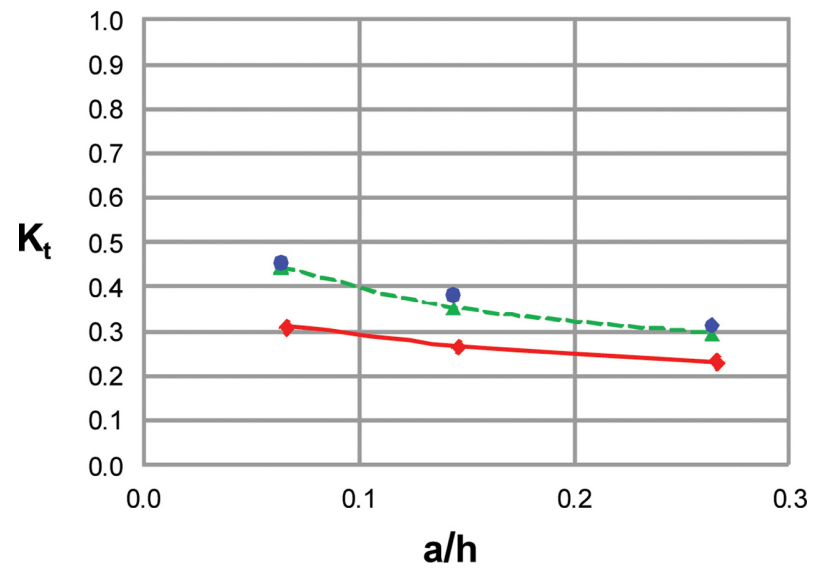

Fig. 3. Variation of transmission coefficients with wave nonlineartiy (Drag resistance coefficients are the same between the Boussinesq equations and the CASMAS-SURF); circle $=$ Vidal et al., solid line with diamond $=$ CADMASSURF, dashed line with triangle $=$ Boussinesq equations.

0.264. The drag resistance coefficients are $\alpha_{l}=800$ and $\alpha_{t}=3$ in the Boussinesq equations and $\alpha_{l E}\left(=\alpha_{l} /[\lambda(1-\right.$ ג)]) $=3250$ and $\mathrm{a}_{t E}=3$ in the CADMAS-SURF.

For the whole experiments, the added mass coefficient which is used in the inertial resistance term is fixed in both the Boussinesq equations and the CADMAS-SURF as $\kappa=0.34$ which was suggested by Lara et al. (2012) for waves in a porous breakwater. It should be known that $\kappa=0.5$ and $\kappa=1$ are for porous layer with spheres and circular cylinders, respectively.

Fig. 3 shows the variation of transmission coefficients with wave nonlinearity. In the figure, the drag resistance coefficients are the same between the Boussinesq equations and the CADMAS-SURF. The numerical solutions of the Boussinesq equations and CADMAS-SURF are compared against the experimental data of Vidal et al. The experimental data shows the decrease of transmission coefficient with the increase of wave nonlinearity. Numerical results of the Boussinesq equations are close to the experimental data because the drag resistance terms have been tuned to fit the numerical results to the experimental data (Vu et al., 2017). However, numerical results of the CADMAS-SURF are smaller than the experimental data which means that the drag resistance coefficients should be tuned to fit to the experimental data.

Second, for solitary waves through a porous breakwater (i.e., one layer case), values of the drag resistance coefficients are determined such that the transmission coefficients of numerical models (both the Boussinesq and Navier-Stokes equations) are close to experimental data. Fig. 4(a) shows that the transmission coefficients of numerical models become (a) transmission coefficient

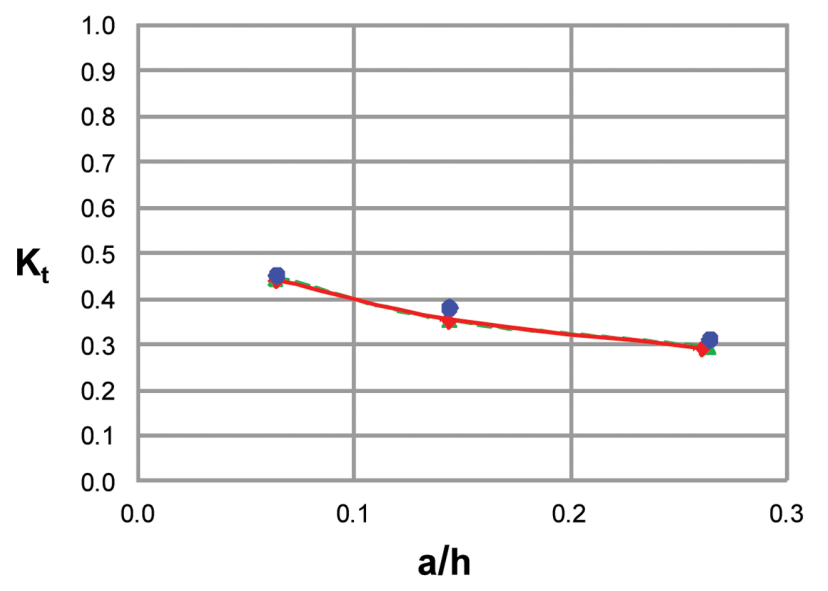

(b) reflection coefficient

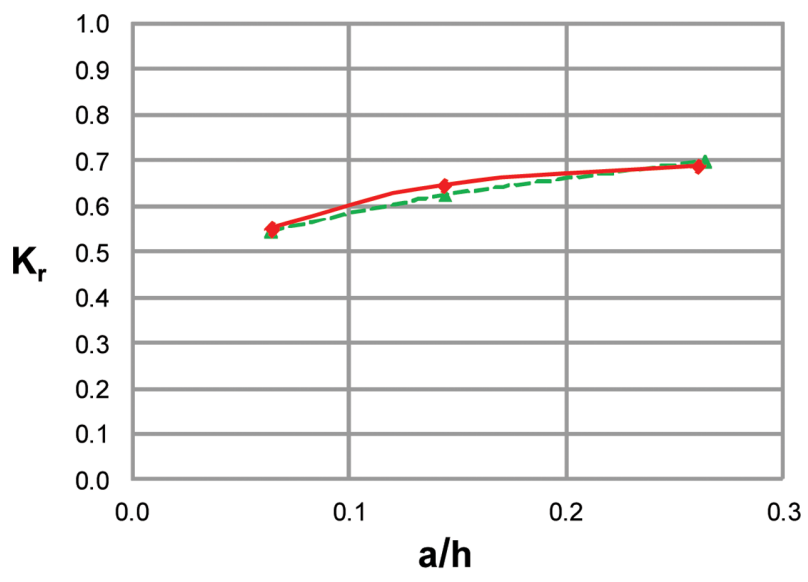

(c) energy dissipation coefficient

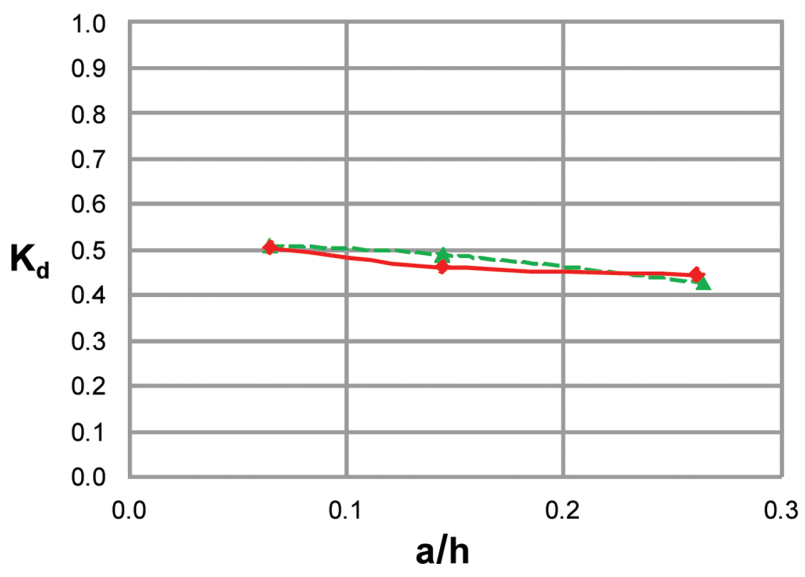

Fig. 4. Variation of transmission, reflection, and energy dissipation coefficients with wave nonlinearity (Drag resistance coefficients are determined to fit experimental data); circle $=$ Vidal et al., solid line with diamond=CADMAS-SURF, dashed line with triangle $=$ Boussinesq equations.

close to the experimental data after finding optimum values of the drag resistance coefficient (i.e., $\alpha_{l}=800$ and $\alpha_{t}=3$ for the Boussinesq equations; $\alpha_{I E}=2000$ and $\alpha_{t E}=0.7$ for the CADMAS-SURF). We use these optimum values of the 
drag coefficient in later numerical experiments.

Fig. 4(b) shows the variation of reflection coefficients with wave nonlinearity with the optimum values of the drag resistance coefficients. It is noticeable that, even without experimental data, the reflection coefficients are close to each other between the Boussinesq equations and the CADMAS-SURF. As wave nonlinearity increases, the reflection coefficient increases. That is because the area of reflection on the wall increases with the increase of wave nonlinearity.

We also investigate the energy dissipation coefficient for waves in a porous breakwater. The energy dissipation coefficient can be defined as

$$
K_{d}=1-K_{t}^{2}-K_{r}^{2}
$$

The energy is proportional to squared wave height and thus the transmission and reflection coefficients which are the ratios of wave heights are squared in Eq. (28).

Fig. 4(c) shows the variation of energy dissipation coefficients with wave nonlinearity with the optimum values of the drag resistance coefficients. It is noticeable that, even without experimental data, the energy dissipation coefficients are close to each other between the Boussinesq equations and the CADMAS-SURF. It is interesting that the energy dissipation coefficient decreases a little with the increase of wave nonlinearity. Figs. 4(a) to 4(c) show that, as wave nonlinearity increases, the increase of the reflection coefficient is more significant than the decrease of the transmission coefficient and thus the energy dissipation coefficient would decrease.

Third, for solitary waves overtopping on a porous breakwater, we find that, with the variation of wave nonlinearity, the height of waves overtopping a low-crested breakwater (obtained by the Navier-Stokes equations) are between the heights of waves passing a high-crested breakwater (obtained by the one-layer Boussinesq equations) and submerged breakwaters (obtained by the two-layer Boussinesq equations). See Fig. 1 for the concept. Three cases with the breakwater crest heights are $h_{c}=60 \mathrm{~cm}$ (high-crested breakwater), $h_{c}=1 \mathrm{~cm}$ (low-crested breakwater), and $h_{c}=-2 \mathrm{~cm}$ (submerged breakwater). Experimental conditions are the same as those of Vidal et al. (1988), i.e., water depth of $h=30 \mathrm{~cm}$, breakwater width of $b=20 \mathrm{~cm}$, porous material size of $d=1.43 \mathrm{~cm}$, porosity of $\lambda=0.44$. Wave nonlinearity is varied as $a / h=0.064,0.144,0.264$.

Fig. 5(a) compares the transmission coefficients among the one- and two-layer Boussinesq equations and the (a) transmission coefficient

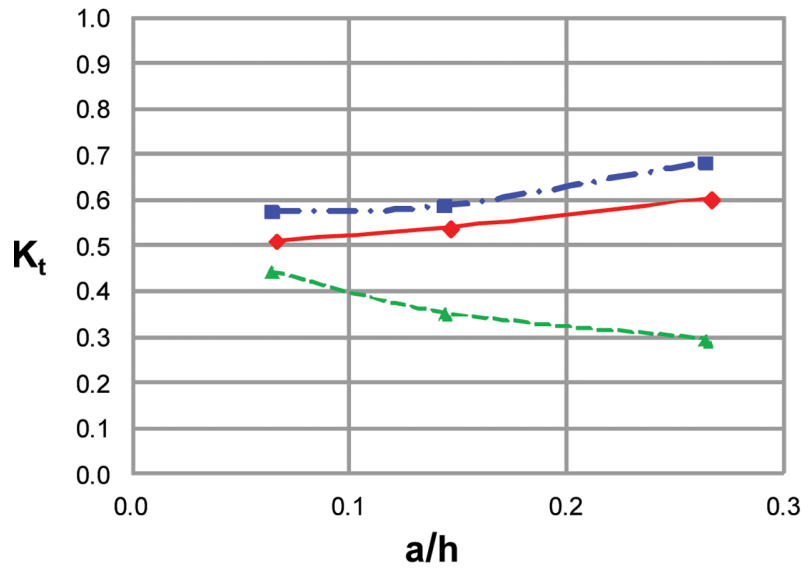

(b) reflection coefficient

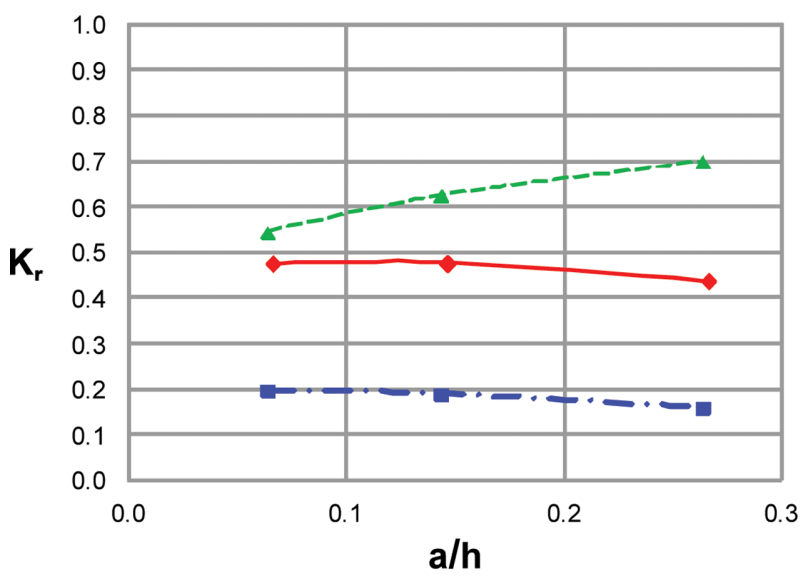

(c) energy dissipation coefficient

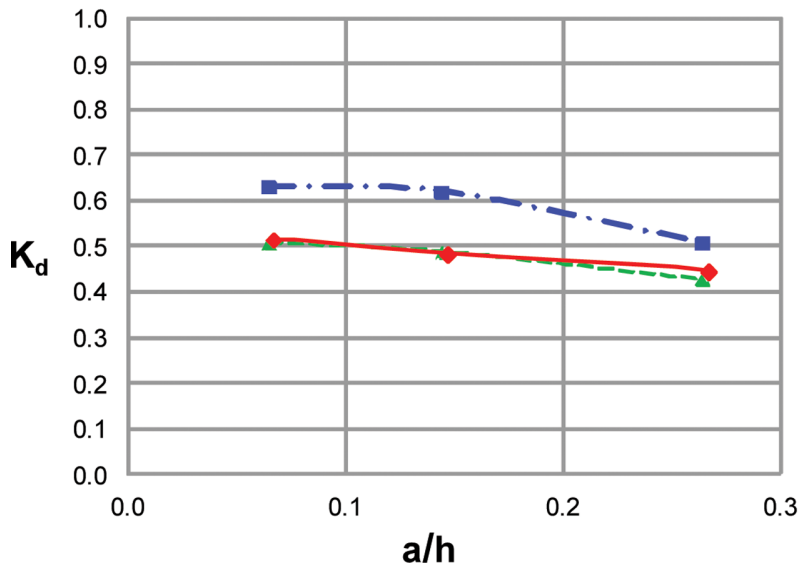

Fig. 5. Comparison of transmission, reflection, and energy dissipation coefficients obtained by the one-layer and two-layer Boussinesq equations and the CADMAS-SURF (wave nonlinearity is varied); solid line with diamond = CADMAS, dashed line with triangle $=$ one-layer Boussinesq equations, dash-dotted line with rectangle $=$ two-layer Boussinesq equations.

CADMAS-SURF. The transmission coefficients of waves overtopping a low-crested breakwater (obtained by the CADMAS-SURF) are greater than those of waves passing 
through a high-crested breakwater (obtained by the one layer Boussinesq equations) and less than those of waves passing through a submerged breakwater (obtained by the two layer Boussinesq equations). For waves with lower wave nonlinearity, overtopping waves can be more accurately predicted using the one-layer and two-layer Boussinesq equations. It is interesting that, with the increase of wave nonlinearity, the transmission coefficient by the one-layer Boussinesq equations decreases while the transmission coefficient by both the two-layer Boussinesq equations and the CADMAS-SURF increases. That is because, for waves over a low-crested breakwater and a submerged breakwater, more highly nonlinear waves have more area above the breakwater crest which would pass through the breakwater without energy dissipation and thus experience more transmission. However, for waves in a high-crested breakwater, more highly nonlinear waves have more area under the breakwater crest which would pass through the breakwater with energy dissipation and thus experience less transmission. As wave nonlinearity becomes smaller, the heights of transmitting waves become closer to each other between the one-layer and two-layer Boussinesq equations and thus become closer to the height of overtopping waves.

Fig. 5(b) compares the reflection coefficients among the one-layer and two-layer Boussinesq equations and the CADMAS-SURF. The reflection coefficients of waves overtopping a low-crested breakwater are less than those of waves passing through a high-crested breakwater and greater than those of waves passing through a submerged breakwater. It is interesting that, with the increase of wave nonlinearity, the reflection coefficient by the one-layer Boussinesq equations increases while the reflection coefficient by both the two-layer Boussinesq equations and the CADMAS-SURF decreases. That is because, for waves over a low-crested breakwater and a submerged breakwater, more highly nonlinear waves have less area below the breakwater crest which would reflect from the breakwater wall and thus experience less reflection. However, for waves in a high-crested breakwater, more highly nonlinear waves have more area under the breakwater crest which would reflect from the breakwater wall and thus experience more reflection.

Fig. 5(c) compares the energy dissipation coefficients among the one-layer and two-layer Boussinesq equations and the CADMAS-SURF. The energy dissipation coefficients increase with the increase of wave nonlinearity. The energy dissipation coefficients are close to each other between the one-layer Boussinesq equations and the CADMAS-SURF. However, the energy dissipation coefficients by the twolayer Boussinesq equations are greater than the those by the

\section{(a) transmission coefficient}

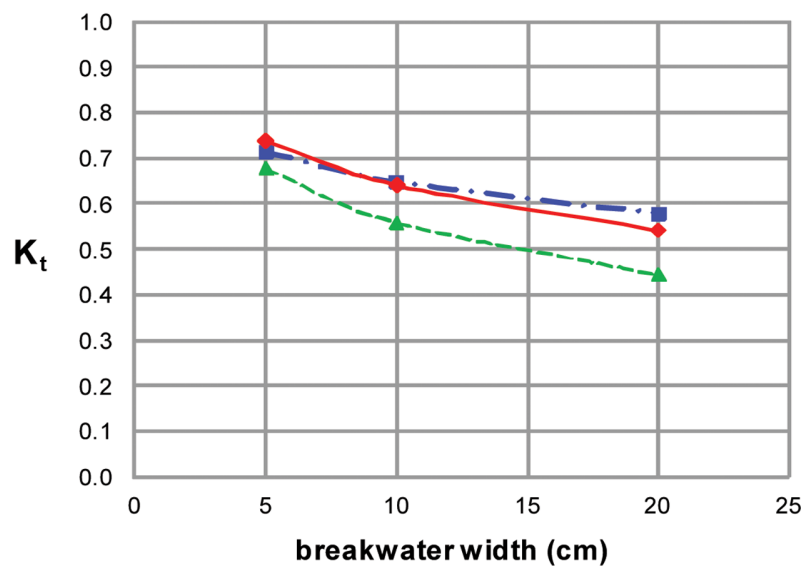

(b) reflection coefficient

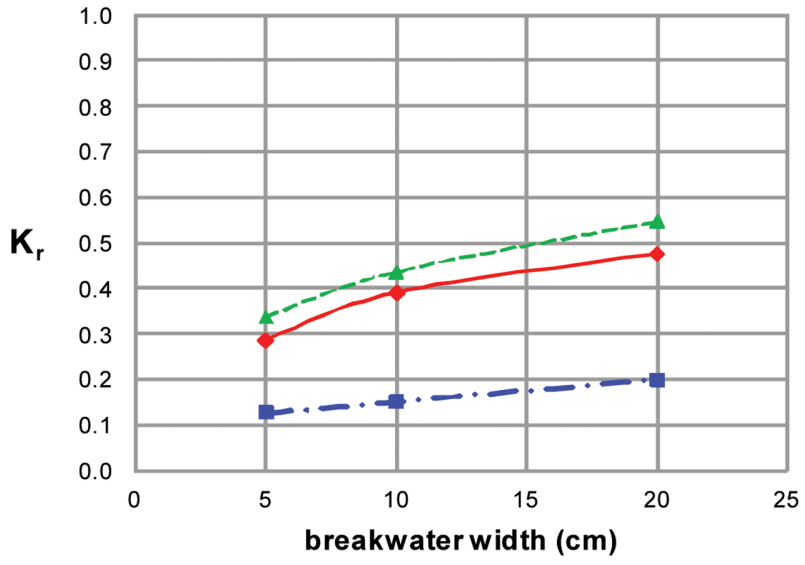

(c) energy dissipation coefficient

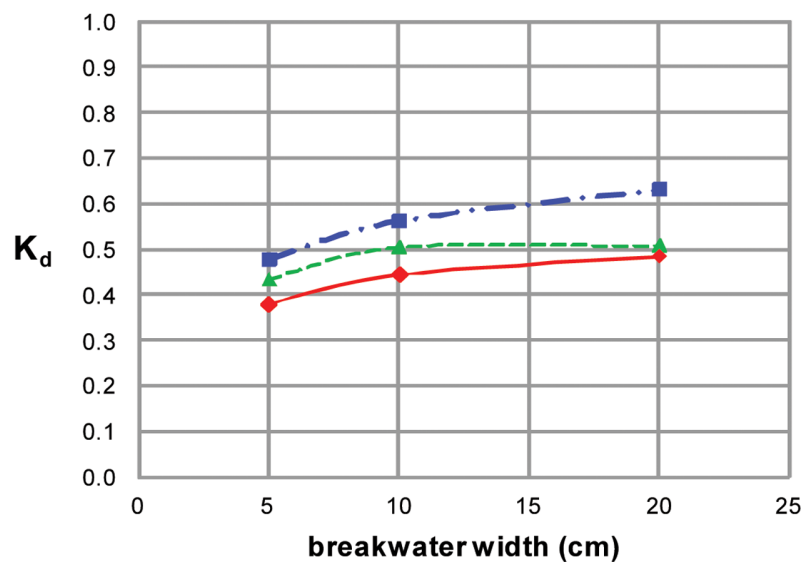

Fig. 6. Comparison of transmission, reflection, and energy dissipation coefficients obtained by the one-layer and two-layer Boussinesq equations and the CADMAS-SURF (breakwater width is varied); solid line with diamond = CADMAS, dashed line with triangle $=$ one-layer Boussinesq equations, dash-dotted line with rectangle $=$ two-layer Boussinesq equations. 
one-layer Boussinesq equations and the CADMAS-SURF.

Fourth, for solitary waves overtopping on a porous breakwater, we find that, with the variation of breakwater width, the height of waves overtopping a low-crested breakwater are between the heights of waves passing a high-crested breakwater and a submerged breakwater. Three cases with the breakwater crest heights are $h_{c}=$ $60 \mathrm{~cm}, 1 \mathrm{~cm},-2 \mathrm{~cm}$. Experimental conditions are the same as those of Vidal et al. (1988), i.e., water depth of $h=$ $30 \mathrm{~cm}$, porous material size of $d=1.43 \mathrm{~cm}$, porosity of $\lambda=0.44$. The breakwater width is reduced from $b=20 \mathrm{~m}$, to $b=15 \mathrm{~m}, 10 \mathrm{~m}, 5 \mathrm{~m}$.

Figs. 6(a) and 6(b) compares transmission and reflection coefficients among the one-layer and two-layer Boussinesq equations and the CADMAS-SURF. As the breakwater width becomes narrower, both the transmission and reflection coefficients of overtopping waves of one-layer and two-layer results become close together. This implies that, for waves on breakwaters with narrower width, overtopping waves can be more accurately predicted using the one-layer and two-layer Boussinesq equations. Fig. 6(c) compares the energy dissipation coefficients among the one-layer and two-layer Boussinesq equations and the CADMAS-SURF. As the breakwater width becomes narrower, the energy dissipation would be negligibly smaller and thus the transmission and reflection coefficients would be near to unity and zero, respectively.

\section{Conclusion}

In the present study, we approximately obtain height of waves overtopping on a porous breakwater using both the one-layer and two-layer Boussinesq equations. We use the one-layer Boussinesq equations of Lee et al. (2014) and we derive the two-layer Boussinesq equations following Cruz et al. (1997). For solitary waves through a porous breakwater (i.e., one layer case), values of the drag resistance coefficients are determined such that the transmission coefficients of numerical models (both the Boussinesq and Navier-Stokes equations) are close to experimental data. Further, we find that the height of waves overtopping on a low-crested breakwater (obtained by the Navier-Stokes equations) are smaller than the height of waves passing through a highcrest breakwater (obtained by the one-layer Boussinesq equations) and larger than the height of waves passing through a submerged breakwater (obtained by the two-layer Boussinesq equations). As wave nonlinearity becomes smaller or the porous breakwater width becomes narrower, the heights of transmitting waves obtained by the one-layer and two-layer Boussinesq equations become closer to the height of overtopping waves obtained by the Navier-Stokes equations. If the water surface elevation is above the breakwater crest, the waves are in two layers, i.e., upper non-porous layer and lower porous layer. If the water surface elevation is below the breakwater crest, the waves are in one porous layer. In the future, we will directly simulate overtopping waves using both one-layer and twolayer Boussinesq equations simultaneously.

\section{Acknowledgments}

This study was performed by a project of "Investigation of large swell waves and rip currents and development of the disaster response system (No. 20140057)" sponsored by the Ministry of Oceans and Fisheries.

\section{References}

CDIT (2001). Research and development of a numerical wave flume; CADMAS-SURF Report of the research group for development of numerical wave flume for the design of maritime structures. Coastal Development Institute of Technology, Japan.

Cruz, E.C., Isobe, M. and Watanabe, A. (1997). Boussinesq equations for wave transformation on porous beds. Coastal Engineering, 30, 125-156.

Engelund, F.A. (1953). On the laminar and turbulent flows of ground water through homogeneous sand. Danish Academy of Technical Sciences.

Ergun, S. (1952). Fluid flow through packed columns. Chemical Engineering Progress, 48, 89-94.

Gingold, R.A. and Monaghan, J.J. (1977). Smoothed particle hydrodynamics: Theory and application to nonspherical stars. Mon. Not. R. Astron. Soc., 181, 375-389.

Lara, J.L., del Jesus, M. and Losada, I.J. (2012). Three-dimensional interaction of waves and porous coastal structures. Part II: Experimental validation. Coastal Engineering, 64, 26-46.

Lee, C., Vu, V.N. and Jung, T.-H. (2014). Extended Boussinesq equations for waves in porous media: Derivation of governing equations and generation of waves internally. Proc. 34th International Conference on Coastal Engineering, Paper No. A12, Seoul.

Lin, P. and Liu, P.L.-F. (1998). A numerical study of breaking waves in the surf zone. Journal of Fluid Mechanics, 359, 239264.

Madsen, P.A. and Sørensen, O.R. (1992). A new form of the Boussinesq equations with improved linear dispersion characteristics. Part 2: A slowly varying bathymetry. Coastal Engineering, 18, 
183-204.

Peregrine, D.H. (1967). Long waves on beach. Journal of Fluid Mechanics, 27, 815-827.

Vidal, C., Losada, M.A., Medina, R. and Rubio, J. (1988). Solitary wave transmission through porous breakwaters. Proc. 21st International Conference on Coastal Engineering, ASCE, 10731083.
Vu, V.N., Lee, C. and Jung, T.-H. (2017). Extended Boussinesq equations for waves in porous water. Coastal Engineering (in revision).

Received 24 November, 2017

Accepted 12 December, 2017 